\title{
Effect of antithrombin III among patients with disseminated intravascular coagulation in obstetrics: a nationwide observational study in Japan
}

\author{
Yudai Iwasaki ${ }^{1}$, Hiroyuki Ohbe ${ }^{2}$, Daisuke Shigemi ${ }^{2}$, Kiyohide Fushimi ${ }^{3}$, and Hideo \\ Yasunaga ${ }^{2}$ \\ ${ }^{1}$ Tohoku University Hospital \\ ${ }^{2}$ The University of Tokyo \\ ${ }^{3}$ Tokyo Medical and Dental University Graduate School
}

February 22, 2021

\begin{abstract}
Abstract Objective: Pregnant women may develop disseminated intravascular coagulation (DIC), possibly resulting in massive maternal haemorrhage and perinatal death. The Japan guideline recommends use of antithrombin III (ATIII) for DIC in obstetrics; however, its effect remains uncertain. The present study therefore aimed to investigate the effect of ATIII for DIC patients in obstetrics, using a national inpatient database in Japan. Design: Nationwide observational study Setting: Japan Population: We used the Diagnosis Procedure Combination inpatient database to identify patients who delivered at hospital and were diagnosed with DIC from July 2010 to March 2018. Methods: Propensity score matching analyses were performed to compare in-hospital maternal mortality and hysterectomy during hospitalization between users and non-users of ATIII on the day of delivery. Main Outcome Measures: In-hospital mortality, hysterectomy Results: A total of 9,920 patients were enrolled, including 4,329 patients (44\%) who used ATIII and 5,511 patients (56\%) who did not use ATIII. One-to-one propensity score matching created 3290 pairs. In-hospital maternal mortality did not differ significantly between the propensity-matched groups ( $0.3 \%$ in the ATIII group vs. $0.5 \%$ in the control group; odds ratio, $0.73 ; 95 \%$ confidence interval, $0.35-1.54$ ). Patients in the ATIII group, compared with those in the control group, had a significantly lower proportion of receiving hysterectomy during hospitalization ( $5.3 \%$ vs. $8.7 \%$; difference, $-2.9 \%$; $95 \%$ confidence interval, -4.2 to $-1.6 \%$ ). Conclusions: The present study did not show mortality-reducing effect of ATIII for patients with DIC in obstetrics. ATIII may have clinical benefit in terms of reduction in receiving hysterectomy.
\end{abstract}

\section{Hosted file}

Manuscript_obs_dic_at3.pdf available at https://authorea.com/users/397259/articles/510195effect-of-antithrombin-\%E2\%85\%B2-among-patients-with-disseminated-intravascularcoagulation-in-obstetrics-a-nationwide-observational-study-in-japan 


\begin{tabular}{|c|c|}
\hline \multicolumn{2}{|c|}{$\begin{array}{l}9,920 \text { patients who delivered at hospital and were diagnosed with } \\
\text { disseminated intravascular coagulation (DIC) } \\
\text { from July } 1,2010 \text {, to March } 31,2018\end{array}$} \\
\hline \multicolumn{2}{|c|}{$\begin{array}{l}80 \text { excluded patients: } \\
2 \text { aged }>50 \text { years old } \\
39 \text { second or subsequent admission who delivered at } \\
\text { hospital and were diagnosed with DIC } \\
1 \text { died on the day of delivery } \\
38 \text { discharged on the day of delivery }\end{array}$} \\
\hline 9,840 eligible patients & \\
\hline $\begin{array}{l}4,329 \text { patients in the } \\
\text { antithrombin III group }\end{array}$ & $\begin{array}{l}5,511 \text { patients in the } \\
\text { control group }\end{array}$ \\
\hline & 1 \\
\hline 3,290 patients matched & 3,290 patients matched \\
\hline
\end{tabular}

